\title{
Kontestasi Pesan Politik dalam Kampanye Pilpres 2014 di Twitter: Dari Kultwit Hingga Twitwar
}

\author{
Mas Agus Firmansyah \\ Program Studi Ilmu Komunikasi Universitas Bengkulu \\ Email:mgs.firmansyah@gmail.com \\ Deddy Mulyana, Siti Karlinah, Suwandi Sumartias \\ FIKOM Universitas Padjajaran
}

\begin{abstract}
During the 2014 presidential election campaign, 95 million election-related chirp has been chirped by Twitter users in Indonesia. One of the causes is the contribution of Twitter account supporters of both candidates. This study aims to identify how the chirp format uploaded by both supporters of the candidate. Using qualitative methods of Critical Technocultural Discourse Analysis (CTDA) to Twitter's Twitter supporter candidate, this research found that in general, there are similarities of chirp format used by both supporters of the candidate. In addition to using a single tweet was also found twitter with kultwit and twitwar formats. The existence of both formats at once shows how the culture of collectivism Indonesian society capable of transforming in the realm of digital Twitter.
\end{abstract}

Keywords: Twitter, Political Messages, Presidential Campaign, Kultwit, Twitwar

\begin{abstract}
Abstrak
Selama masa kampanye pilpres tahun 2014, tercatat 95 juta kicauan terkait pemilu telah dikicaukan oleh pengguna Twitter di Indonesia. Salah satu penyebabnya adalah kontribusi dari kicauan akun Twitter pendukung kedua capres. Penelitian ini bertujuan untuk mengidentifikasi bagaimana format kicauan yang diunggah oleh kedua pendukung capres. Dengan menggunakan metode kualitatif berupa Critical Technocultural Discourse Analysis (CTDA) terhadap kicauan akun Twitter pendukung capres, penelitian ini menemukan bahwa secara umum, terdapat kesamaan format kicauan yang digunakan oleh kedua pendukung capres. Selain menggunakan kicauan tunggal (twit) ditemukan pula kicauan dengan format kultwit dan twitwar. Keberadaan kedua format tersebut sekaligus menunjukkan bagaimana budaya kolektivisme (guyub) masyarakat Indonesia mampu bertransformasi di ranah digital Twitter.
\end{abstract}

Kata Kunci: Twitter, Pesan Politik Kampanye pilpres, Kultwit, Twitwar 


\section{Pendahuluan}

Berdasarkan data yang dilansir Twitter, sejak awal masa kampanye pilpres hingga hari pencoblosan / 9 Juli 2014 tercatat ada 95 juta kicauan yang berkaitan dengan pemilu telah dikicaukan oleh pengguna Twitter di Indonesia (detik.com, 13/07/2014). Bahkan, kicauan mengenai kandidat capres yang diunggah oleh akun Twitter@DennyJA_WORLD berhasil menduduki posisi kedua / runer up golden twit sebagai kicauan terbanyak No.2 sedunia yang diretweet ulang oleh pengguna Twitter (m.tempo.co, 13/12/2014). Banyaknya kicauan mengenai pilpres Indonesia di Twitter, selain dikarenakan antusiasme masyarakat juga tidak bisa dilepaskan dari kontribusi kicauan akun Twitter pendukung kedua pasangan capres dalam memperbincangkan capres yang mereka dukung.

Pada negara-negara maju, fenomena penggunaan Twitter sebagai saluran kampanye politik telah banyak diteliti. Boynton et al (2014) mencatat bahwa riset mengenai Twitter telah dimulai sejak sekitar awal tahun 2008-2009. Beberapa diantaranya seperti yang dilakukan oleh Connover (2011) yang mengkaji polarisasi politik di Twitter pada saat pemilihan anggota kongres Amerika Serikat tahun 2010, Vergeer dan Hermans (2013) yang meneliti penggunaan Twitter pada pemilihan umum di Belanda tahun 2010 atau Boynton et al sendiri (2014) yang mengkaji pola arus kicauan komunikasi politik pada pengguna Twitter diAmerika Serikat. Namun demikian, untuk negara berkembang khususnya Indonesia, Mulyana (2013) dan Nugroho (2011) menyebutkan bahwa penelitian yang melibatkan penggunaan internet maupun media sosial untuk kepentingan komunikasi politik masih sangat terbatas. Hal itu menyebabkan informasi mengenai pola pengunaan internet dan media sosial untuk kepentingan komunikasi politik di Indonesia menjadi sangat sedikit yang terpublikasi secara ilmiah.

Secara umum, beberapa publikasi penelitian yang berhubungan dengan penggunaan internet di Indonesia misalnya seperti kajian
Lim (2012) yang meneliti penggunaan blog oleh masyarakat muslim, Nugroho (2012) mengkaji aktivisme masyarakat sipil dalam penggunaan media sosial. Sementara itu, Mulyana (2013) menyebutkan bahwa media sosial di Indonesia setidaknya mulai ramai diperbincangkan dan dikaji baru pada tahun 2012 saat perhelatan pemilihan Gubernur DKI Jakarta berlangsung.

Ketika memasuki kampanye pilpres 2014, fenomena penggunaan Twitter sebagai saluran komunikasi politik ini kemudian mulai ramai diperbincangkan dan dikaji. Hal ini dikarenakan untuk pertama kalinya, Twitter digunakan secara masif bukan hanya oleh netizen, namun juga oleh kandidat capres dan para pendukungnya. Kampanye pilpres 2014 di Indonesia pada gilirannya menjadikan lanskap media sosial Twitter sebagai fenomena menarik tersendiri, sehingga Peter Greenberger direktur politik global Twitter menyempatkan hadir untuk menemui kedua kandidat capres dan mengatakan bahwa; "Indonesia merupakan contoh besar bagaimana Twitter merevolusi politik, dan kami sangat berharap akan pemilihan Indonesia dengan Twitter untuk pertama kalinya di Indonesia" (detik.com, 3/06/2014).

Faktor kehadiran Twitter yang dipergunakan secara masif ini menjadikan wajah kampanye pilpres 2014 berbeda dengan kampanye pada pemilu tahun-tahun sebelumnya. Berdasarkan catatan Mulyana (2013:77) disebutkan bahwa kampanye politik di Indonesia 1999, 2004 dan 2009 partai politik dan kandidat politik telah menampilkan panggung depannya dengan semarak, lewat unjuk kekuatan partai dalam bentuk arak-arakan di jalanan, pidato, di panggung hiburan, lewat spanduk dan baliho dan dalam debat antar calon presiden dan antar calon wakil presiden.

Seiring dengan perubahan dan perkembangan teknologi informasi, khususnya kehadiran media sosial pada gilirannya menuntut strategi baru bagi kandidat capres dan para pendukungnya untuk dapat berkomunikasi dengan masyarakat pemilih maupun dengan konstituen pendukungnya. Situasi ini menjadikan 
lanskap media sosial kemudian menjadi saluran kampanye politik yang ramai digunakan oleh kandidat capres dan para pendukungnya.

Dalam konteks inilah fenomena kampanye pilpres 2014 di media sosial ramai dikaji. Beberapa diantaranya seperti kajian yang berfokus pada kampanye kreatif yang dilakukan Arianto (2015) hingga penelitian yang mengkaji kampanye hitam di media sosial seperti yang dilakukan Budiman (2014). Sementara itu, kajian spesifik mengenai penggunaan Twitter pada saat kampanye pilpres 2014 lebih banyak dilakukan oleh lembaga social media monitoring seperti indexpolitica dan politicalwave yang bertujuan untuk memetakan sentimen dukungan netizen kepada pasangan capres. Metode yang digunakan oleh lembaga social media monitoring ini dapat dikategorikan ke dalam non scientific research (lihat, Abgugaza 2013). Selain itu, hasil kajian yang dilakukan oleh lembaga social media monitoring ini hanya dipublikasikan dalam bentuk press release di media massa maupun website mereka. Karenanya, publikasi ilmiah terkait penggunaan Twitter di Indonesia dapat dikatakan masih sangat terbatas.

Pengguna Twitter di Indonesia sendiri dikenal memiliki pola karakteristik yang unik dan khas dalam mengunggah kicauan (tweet). Salah satu contohnya adalah penggunaan format kultwit dan twitwar yang ramai digunakan oleh pendukung kedua capres pada saat kampanye pilpres 2014. Terminologi kultwit telah dikenal luas oleh pengguna Twitter di Indonesia sebagai bentuk penyampaian informasi layaknya "kuliah" dengan cara membuat kicauan secara berseri. Sementara twitwar dikenal sebagai bentuk perang kicauan atau saling menyindir dengan cara menyerang antar akun Twitter. Selama masa kampanye pilpres 2014, kedua format kicauan berupa kultwit dan twitwar ini menjadi bagian dari pola pesan politik yang seringkali diunggah oleh akun Twitter pendukung capres.

Fenomena penggunaan format kicauan berupa kultwit dan twitwar inilah yang kemudian dijadikan kajian dalam tulisan ini. Fokus utamanya adalah mengidentifikasi bagaimana format kultwit dan twitwar yang diunggah oleh akun Twitter pendukung kedua pasangan capres selama berlangsungnya masa kampanye pilpres 2014 (4 Juni s/d 5 Juli). Secara lebih spesifik lagi, penelitian ini mengkaji mulai dari bagaimana format kultwit dan twitwar digunakan oleh kedua pendukung capres hingga bagaimana kedua format tersebut dapat hadir ditinjau dari aspek sosio kultural masyarakat Indonesia.

\section{Metode Penelitian}

Penelitian ini menggunakan metode kualitatif dengan menjadikan observasi dan pengamatan terhadap kicauan dari akun Twitter pendukung capres sebagai unit analisisnya. Penetapan akun Twitter pendukung capres yang dijadikan unit analisis menggunakan teknik purposive sampling atau sample bertujuan, yang ditetapkan dengan pertimbangan dan kriteria sebagai berikut; (1) akun twitter yang dimiliki politisi maupun relawan yang telah teridentifikasi mendukung salah satu kandidat capres, dan (2) pernah mengunggah kicauan dalam bentuk format kultwit dan juga pernah terlibat twitwar dengan akun Twitter pendukung capres lainnya. Oleh sebab itu, data dan unit analisis yang akan dikaji dalam penelitian ini adalah kicauan / percakapan yang menggunakan format kultwit dan twitwar yang diunggah oleh kedua akun Twitter pendukung capres selama masa kampanye pilpres berlangsung (4 Juni s/d 5 Juli 2014).

Untuk analisisnya penelitian ini menggunakan teknik Critical Technocultural Discourse Analysis (CTDA) dari Brock (2012, 2016). Secara teoritis, CTDA merupakan hasil integrasi dari berbagai kajian keilmuan; mulai dari kajian teknologi, kajian komunikasi hingga kajian kritis yang bertujuan untuk memahami bagaimana budaya membentuk teknologi (lihat, Brock 2012). Menurut Brock (2016) CTDA adalah teknik analisis terintegrasi yang dapat digunakan untuk mengkaji keterkaitan antara artefak teknologi dengan wacana penggunanya yang dibingkai oleh teori budaya untuk membongkar hubungan semiotik dan 
material, fungsi, kepercayaan serta makna teknologi infomasi bagi penggunanya. Aplikasi penggunaan CTDA ini pernah dilakukan Brock (2012) untuk mengkaji bagaimana masyarakat kulit hitam Amerika dalam menggunakan Twitter layaknya percakapan lisan. Dalam konteks penelitian ini, maka CTDA digunakan untuk mengkaji bagaimana format kultwit dan twitwar digunakan oleh pendukung kandidat capres dalam kampanye pilpres 2014 dapat terbentuk dilihat dari aspek sosial budaya masyarakat Indonesia.

\section{Hasil dan Pembahasan}

\section{Format Kicauan Pendukung Capres}

Secara umum, hasil penelitian menunjukkan bahwa pesan politik yang dikicaukan oleh akun Twitter pendukung Prabowo-Hatta maupun akun Twitter pendukung Jokowi-JK menggunakan beragam format kicauan yang relatif hampir seragam. Mulai dari penggunaan format kicauan biasa (twit), penggunaan tanda pagar (hastag\#), kicauan berupa upload foto (twitpic) atau video hingga retweet dan tweet infografis. Untuk lebih jelas lagi, berikut ini ditampilkan beberapa contoh format masing-masing akun Twitter kedua pendukung pasangan capres dalam mengunggah kicauan selama masa kampanye pilpres 2014 berlangsung.

Berbagai format kicauan yang diunggah melalui akun Twitter pendukung capres dapat dikatakan merupakan bentuk ekspresi dukungan kepada sang kandidat. Selama masa kampanye pilpres 2014, tidak sedikit berbagai bentuk ekspresi dukungan kepada pasangan capres ini kemudian bergulir menjadi trending topic di Twitter. Karenanya, kontestasi dalam mengunggah pesan politik yang dikicaukan oleh kedua pendukung pasangan capres ini juga menyasar dalam perebutan trending topic. Tujuannya adalah agar ekspresi dukungan dengan frasa / kalimat tertentu kepada sang capres dapat menjadi trending topic. Akses dari kontestasi perebutan trending topic tersebut menyebabkan pasukan cyber pendukung kedua capres kemudian banyak yang menggunakan akun bot / robot untuk berkicau dengan tema / topik tertentu mengenai capres yang mereka dukung maupun capres lawan.

Akun bot / akun robot adalah akun Twitter yang diseting oleh pemiliknya untuk mengirimkan twit / kicauan secara otomatis. Biasanya akun ini hanya berkicaun / mentwit dengan isi kicauan yang sudah diseting,

Tabel 1. Format Kicauan Pendukung Capres

\begin{tabular}{|l|l|}
\hline $\begin{array}{c}\text { Akun Twitter } \\
\text { Pendukung Capres }\end{array}$ & \multicolumn{1}{|c|}{ Format Konten Kicauan Twitter } \\
\hline Pendukung Prabowo & $\begin{array}{l}\text { Twit / kicauan berupa; (Hastag \#, video, link url, foto, } \\
\text { infografis, tabel, meme) Perang Kicauan (twitwar), } \\
\text { Kuliah melalui twitter (kultwit), retweet, mention akun } \\
\text { pseoudonim /akun anonim @TrioMacan_2000 dan } \\
\text { akun parpol pengusung capres atau akun pendukung } \\
\text { lainnya }\end{array}$ \\
\hline Pendukung Jokowi & $\begin{array}{l}\text { Twit / kicauan berupa; (Hastag \#, video, link url, } \\
\text { foto, infografis, tabel, komik, meme) Perang Kicauan } \\
\text { (twitwar), Kuliah melalui twitter (kultwit), retweet } \\
\text { / mention akun pseoudonim /akun anonim @ } \\
\text { PartaiSocmed dan akun parpol pengusung capres atau } \\
\text { akun pendukung lainnya }\end{array}$ \\
\hline
\end{tabular}

Sumber: Hasil Penelitian 2015 
sehingga kicauannya terlihat seragam. Akun bot / akun robot ini disinyalir meningkat pada saat kampanye pilpres 2014. Menurut catatan ictwatch.com (2015) akun bot yang muncul dan berkicau pada masa kampanye pilpres 2014 teridentifikasi sebanyak 27.000 akun. Keberadaan akun bot / robot dalam kampanye pilpres 2014 ini pernah disinggung oleh akun@ ulinyusron yang menjadi pendukung Jokowi-JK seperti dapat dilihat pada gambar berikut; berseri. Menurut catatan Parikesit dalam kolom telematika yang dipublikasikan portal pemberitaan detik.com (2013) disebutkan bahwa; "format penyajian kultwit adalah layaknya seperti seorang dosen yang menguliahi mahasiswanya, yaitu followersnya sendiri. Kultwit bukanlah citizen journalism, namun lebih kepada membagi ilmu pengetahuan atau wawasan yang kita miliki kepada publik.

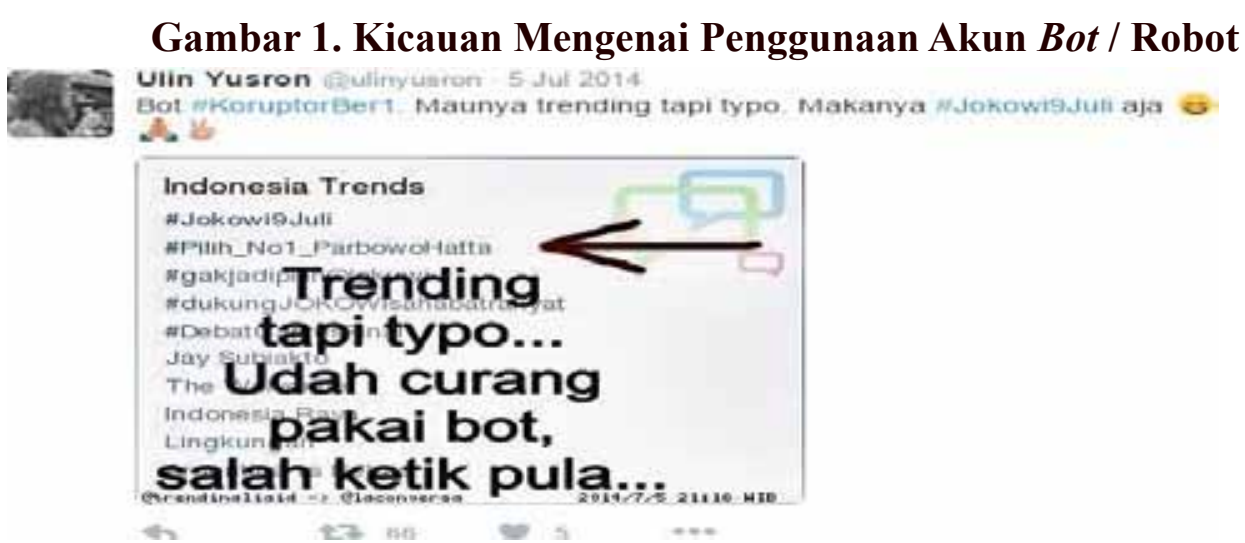

Sumber: Hasil Penelitian, 2015

Karena itu dapat dikatakan bahwa trending topic yang terjadi pada masa kampanye pilpres 2014 belum tentu disebabkan oleh kicauan dari akun real pendukung capres yang berkicau secara natural, akan tetapi dapat pula disebabkan karena keberadaan akun bot yang secara sengaja dibuat untuk berkicau dengan topik tertentu dengan tujuan agar perbincangan mengenai capres yang didukung dapat menjadi trending topic di Twitter. Selain pertarungan dalam membuat frasa tertentu agar dapat menjadi trending topic, kontestasi pesan politik di Twitter ini juga banyak yang menggunakan format kuliah melalui Twitter atau disebut dengan terminologi kultwit dan perang kicauan atau perang argumen yang dikenal dengan istilah twitwar.

\section{Kontestasi Pesan Politik: Dari "Kultwit" hingga"Twitwar"}

Kultwit telah dikenal luas oleh pengguna Twitter di Indonesia sebagai bentuk penyampaian informasi, ekspresi maupun sikap mengenai suatu peristiwa dalam format penggalan kicauan
Penyajian kultwit umumnya tidak real time, dalam arti ia membahas event yang sudah lama lewat, dan menambahkan penafsiran atau tanggapan terhadap event itu"

Kultwit tersebut terkadang diberikan nomor twit, dan bukanya tidak mungkin bisa sampai ratusan nomor. (detik.com, 2013).

Unggahan kicauan dengan menggunakan format kultwit memang telah menjadi karakteristik khas bagi pengguna Twitter di Indonesia. Penelitian ini menemukan bagaimana format kultwit digunakan oleh akun Twitter pendukung kedua pasangan capres untuk mengunggah pesan politik yang berisi dukungan maupun serangan kepada capres lawan dalam bentuk kicauan berseri. Dalam format kultwit yang diunggah oleh akun Twitter pendukung capres, akan dapat dijumpai bentuk kicauan yang diunggah secara berseri mulai dari yang berjumlah puluhan bahkan hingga mencapai 
ratusan kicauan.

Beberapa contoh bentuk format kuliah Twitter (kultwit) yang dikicaukan oleh akun Twitter pendukung capres biasanya ditandai dengan urutan no kicauan, bisa menggunakan angka $(1,2,3)$ ataupun huruf $(a, b, c)$, dan seringkali pula ditandai dengan tanda pagar (hastag \#) yang melekat pada kata / frasa tertentu. Perbedaan dalam penggunaan angka atau huruf sebagai penanda serial kultwit tampaknya disebabkan karena masalah selera si pemilik akun saja. Terkadang didapatkan pula akun Twitter informan pendukung pasangan capres yang menggunakan format kultwit secara bergantian menggunakan huruf dan angka untuk menandai kicauan berseri yang diunggahnya. Berikut ini adalah salah satu format kicauan berupa kultwit yang diunggah oleh akun Twitter pendukung Prabowo-Hatta; penggunaan format kultwit diantara akun Twitter pendukung kandidat capres biasanya hanya pada penggunaan huruf/ angka saja sebagai penanda kicuan yang bersambung. Untuk contoh format kultwit yang menggunakan serial huruf $(\mathrm{a}, \mathrm{b}, \mathrm{c})$ misalnya dapat dilihat pada kicauan akun Twitter @fadjroel yang menjadi pendukung Jokowi-JK seperti ditunjukan pada gambar 3 .

Pada gambar 3 terlihat bagaimana format kultwit yang dikicaukan oleh akun@fadjroel menggunakan serial huruf kapital $(\mathrm{A}, \mathrm{B}, \mathrm{C})$ dengan tambahan hastag \#2JariSabar dan tanda $\sim$ FR sebagai inisial dari Fadjroel Rachman si pemilik akun. Format kultwit yang dikicaukan akun@fadjroel lebih mengarah pada upaya defensif terhadap serangan kampanye hitam berupa fitnah soal PKI di Twitter yang diarahkan pada Jokowi.

\section{Gambar 2. Kultwit Pendukung Prabowo Menggunakan Serial Angka}

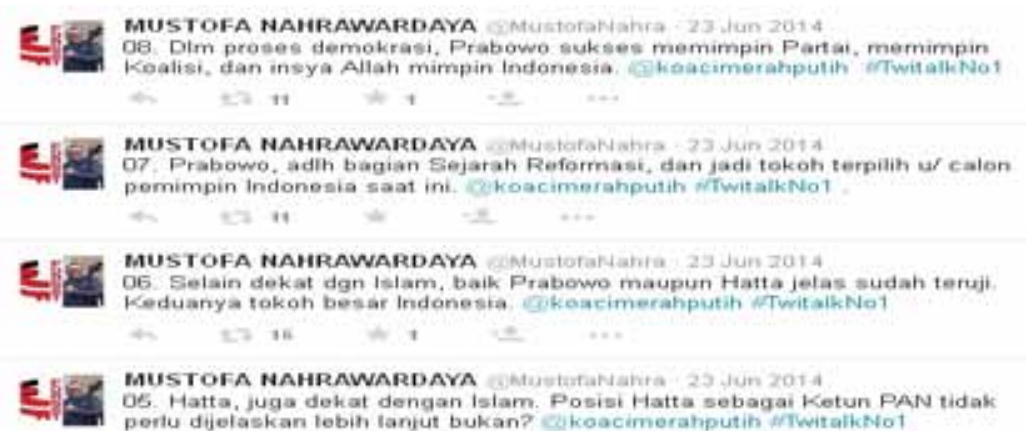

\section{Sumber: Hasil Penelitian 2015}

Gambar di atas adalah contoh kicauan yang berformat kuliah Twitter / kultwit yang dikicaukan oleh akunTwitter@MustofaNahra yang belakangan kemudian berganti dengan nama akun menjadi@Mustofalemon. Sebagai salah satu pendukung Prabowo-Hatta, kicauan akun@MustofaNahra / @mustofalemon yang berformat kultwit tersebut lebih bersifat penyampaian informasi mengenai sosok Prabowo-Hatta. Format yang digunakan dalam kultwit-nya menggunakan angka $(1,2,3)$ dan tanda pagar / hastag \#TwittalkNol sebagai penanda serial / sambungan kicauan yang berisi penggalan informasi mengenai kapasitas dan kapabilitas ketokohan sosok Prabowo dan Hatta. Perbedaan gaya (style) dalam
Beberapa akun twitter pendukung Prabowo-Hatta yang teridentifikasi sering menggunakan format kultwit ini diantaranya seperti akun;@fadlizon,@mustofanahra /@ tofalemon, dan akun@fahrihamza. Untuk akun Twitter pendukung Jokowi-JK, format kultwit biasa dipergunakan oleh akun; @ fadjroel,@ulinyusron@IndraJPiliangdan@ budimandjatmiko. Dalam mengunggah kicauan berformat kultwit ini, beberapa akun Twitter pendukung kedua pasangan capres biasanya juga menyertakan tautan (link Url's) sebagai sumber informasi yang bertujuan untuk menyampaikan data maupun klarifikasi atas pemberitaan yang sedang hangat dibicarakan di media massa arus utama. 


\section{Gambar 3. Kultwit Pendukung Jokowi Menggunakan Serial Huruf}

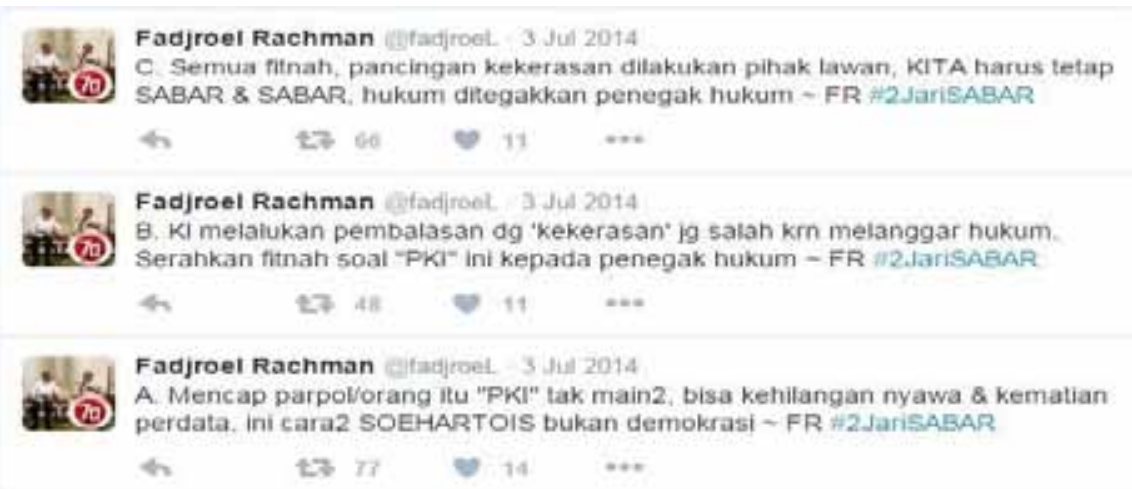

Sumber: Hasil Penelitian, 2015-2016

Sementara itu, isi konten kicauan dari kultwit yang diunggah oleh akun Twitter pendukung kedua pasangan capres sangatlah beragam. Mulai dari informasi keberhasilan mengenai sang capres, klarifikasi dari pendukung kandidat, hingga negative campaign yang berisi fakta-fakta negatif/ kejelekan sang kandidat yang diarahkan untuk menyerang capres lawan. Secara umum, penggunaan format kultwit oleh kedua akun Twitter pendukung capres juga digunakan untuk menyampaikan informasi, klarifikasi atau bahkan digunakan untuk menyerang capres lawan.

Penggunaan format kultwit memang memiliki kemampuan untuk menjelaskan secara panjang lebar mengenai suatu persoalan. Jadi, dalam konteks kampanye pilpres 2014, format ini acapkali digunakan untuk menjelaskan mengenai prestasi kandidat, klarifikasi mengenai persoalan yang menerpa kandidat hingga penyajian informasi yang mengarah pada penyampaian kampanye negatif (negative campaign) atau mengenai kelemahan capres lawan. Dengan demikian, format kultwit yang diunggah oleh akun Twitter pendukung kedua capres selama masa kampanye dapat juga dikatakan semacam bentuk narasi tandingan mengenai kandidat capres yang mereka usung atas narasi yang terbentuk baik lewat media massa arus utama ataupun kicauan akun Twitter lawan.

Model kicauan yang berformat kultwit sekaligus menunjukan kreatifitas pengguna
Twitter di Indonesia yang mencoba mensiasati keterbatasan karakter huruf yang hanya 140 karakter menjadi pengalan-pengalan kicauan dengan konteks tertentu secara berseri. Dalam format kultwit, akan dapat dijumpai bentuk kicauan yang diunggah secara berseri mulai dari yang berjumlah puluhan bahkan hingga mencapai ratusan kicauan.

Sementara itu, perang kicauan atau dikenal oleh pengguna Twitter di Indonesia dengan terminologi twitwar adalah suatu format kicauan yang bersifat menyerang / menyindir dengan cara saling menanggapi kicauan (twit) atau perang argumentasi antar pendukung kandidat satu sama lain. Kicuan (twit) dengan format twitwar ini biasanya akan menjadi ramai ketika ada salah satu kandidat capres maupun pendukungnya tersandung masalah, seperti kesalahan dalam bertindak ataupun berucap. Selain itu, format twitwar yang dilakukan oleh kedua pendukung kandidat capres ini acapkali juga berupa bentuk kicauan saling sindir dengan cara me-mention ataupun no-mention. Apabila twitwar dengan format saling me-mention ditujukan langsung pada sang pemilik akun, maka format no-mention tidak secara langsung diarahkan pada pemilik akun. Karena itu format no-mention lebih bersifat menyindir dengan kata bersayap namun sebenarnya diarahkan / ditujukan pada sebuah akun Twitter pendukung capres lawan. Salah satu contoh bentuk twitwar pada masa kampanye pilpres 2014 seperti dapat 
dilihat pada gambar berikut ini;

seperti; akun@fahrihamza yang mendukung

\section{Gambar 4. Twitwar antara Pendukung Prabowo-Jokowi}

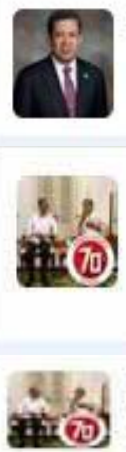

\#70Tahunlndonesia @Fahrihamzah.2 Jul

Saya mendirikan pesantren tidak satu dua...tapi dituduh anti pesantren oleh

orang yg perlu suara santri. \#sinting!

Fadjroel Rachman @fadjoel-2 Jul 2014

oooh jadi ustad @fahrihamzah @PKSejahtera tidak mau minta maaf kepada

santri2 karena penghinaannya, kita lihat seberapa keras kepalanya..

Fadjroel Rachman Eifadiroel ; 2 Jul 2014

Oalah ustad pendiri pesantren toh? Tp cangkemmu itu tho, tak berbau

pesantren : (RT (a) Fahrihamzah: Saya mendirikan pesantren tidak satu dua

\section{Sumber: Hasil Penelitian, 2015-2016}

Format twitwar diatas merupakan perang kicauan antara Fahri Hamzah yang menjadi pendukung Prabowo-Hatta dengan Fadjroel Rachman yang mendukung Jokowi-JK. Twitwar / perang kicauan antara Fahri Hamzah dan Fadjroel merupakan perkembangan dari kicauan Fahri Hamzah sebelumnya mengenai Jokowi yang menjanjikan 1 Muharam sebagai hari santri yang kemudian membesar menjadi kontroversi. Melalui penggunaan hastag (\#) "sinting" nya FahriHamzah seolah berupaya untuk mengatakan bahwa janji Jokowi mengenai hari santri adalah suatu bentuk kesintingan. Kicauan inilah yang kemudian menimbulkan kontroversi dikalangan santri yang kemudian sempat menjadi sasaran publikasi media massa, dimana Fahri Hamzah diberitakan ramai didemo para santri.

Menurut catatan detik.com (14/06/2014) twitwar sudah mulai terjadi setelah pemilu legislatif berlangsung. Perang kicauan / twit pasca pemilu legislatif masih bersifat sporadis dikarenakan belum jelasnya peta koalisi dan kandidat yang akan diusung maju menjadi kandidat capres. Setelah penetapan capres dan cawapres hingga masa kampanye dan hari $\mathrm{H}$ pencoblosan, twitwar kemudian semakin ramai hingga melibatkan akun milik elite politik pendukung kedua pasangan capres. Beberapa akun Twitter pendukung kedua pasangan capres yang pernah saling terlibat twitwar diantaranya
Prabowo-Hatta dengan akun@fadjroel pendukung Jokowi-JK, akun@RatnaSpaet yang mendukung Prabowo-Hatta dengan akun @Fadjroel serta akun@fadlizon yang menjadi pendukung Prabowo-Hatta dengan akun @ indrajpiliang yang mendukung Jokowi-JK.

Konten perang kicauan (twitwar) yang terjadi selama masa kampanye pilpres 2014 bukan hanya berisi konten kicauan yang menyerang pasangan capres saja, namun juga menyasar kepada diri individu si pendukung, termasuk juga mengarah pada elite politik maupun media massa yang berafiliasi serta partai politik yang menjadi pengusung sang kandidat capres. Karenanya perang kicauan (twitwar) yang terjadi diantara akun Twitter pendukung capres dalam kampanye pilpres dapat dikatakan masih berlangsung sporadis, karena menyasar bukan hanya pada pasangan capres yang sedang berkompetisi, namun juga hampir pada semua yang berafiliasi dengan sang capres. Beberapa contoh serangan yang diarahkan pada media massa maupun partai politik misalnya seperti dapat dilihat pada kicauan akun Twitter informan berikut ini;

Dengan mengamati perang kicauan (twitwar) yang terjadi antar akun Twitter pendukung pasangan capres diketahui bahwa isu yang sering diperdebatkan biasanya adalah topik-topik politik yang sedang hangat terjadi atau sedang menjadi 


\section{Sumber: Hasil Penelitian, 2015-2016}

sorotan media massa. Seperti misalnya twitwar yang terjadi antara akun@fahrihamza dengan akun@fadjroel yang berdebat mengenai hari santri. Atau antara akun @ypaonganan dengan @budimandjatmiko yang menanggapi mengenai cara Prabowo dan Jokowi dalam debat capres. Hasil ini sekaligus menunjukan bahwa terdapat keterkaitan antara topik politik yang sedang hangat dibahas di ruang offline dengan di ruang online ataupun sebaliknya. Temuan ini selaras dengan kajian yang dilakukan Boynton, et al (2014) yang menyebutkan bahwa ada keterkaitan antara arus pesan politik yang bersirkulasi di Twitter dengan berbagai informasi yang terjadi di ruang offline.

Namun demikian, tidak sedikit pula kicauan berupa twitwar ini kemudian meluas hingga menjadi pertengkaran fisik di dunia nyata. Fenomena twitwar antar pendukung capres yang terjadi pasca pelaksanaan pilpres ini kemudian dapat juga berkembang menjadi pertengkaran fisik sehingga ramai menjadi sorotan dan publikasi media massa. Sebagaimana diberitakan oleh portal pemberitaan online m.liputan6.com pada tanggal 12 Februari 2015 dengan judul berita "Heboh Twitwar Mobnas Berujung Duel Di Istora Senayan”. Dalam pemberitaan tersebut disebutkan;

"Twitwar atau debat di Twitter berujung duel menghebohkan lini masa. Perkelahian tangan kosong 1 lawan 1 itu dilakukan antara pemilik akun@ redinparisdan@panca66 di Istora Senayan Jakarta, Rabu 11 Februari malam". Berdasarkan lini masa 2 akun tersebut, duel keduanya bermula dari perdebatan terkait Proton yang diisukan bakal menjadi mobil nasional.Akun@ redinparis menganggap MoU Proton dengan perusahaan milik Hendropriyono yang disaksikan Presiden Jokowi itu hanya bisnis. Namun, pendapat itu mendapatkan pertentangan dari@ panca66yang berujung padakesepakatan untuk berkelahi.

(m.liputan6.com, 12/2/2015).

Fenomena twitwar di Twitter ini juga tidak bisa dilepaskan dari adanya faktor sistem sosial budaya masyarakat Indonesia yang berbasis komunal dan budaya lisan. Indikasi bagaimana faktor budaya komunal dan lisan menjadi salah satu karakteristik unik pengguna media sosial di Indonesia dengan sangat mudah ditemukan pada acara-acara komunitas yang terbentuk secara online. Meskipun interaksi dan komunikasi antar anggota sebuah komunitas telah diwadahi oleh media sosial secara online namun keinginan untuk berkumpul secara offline / kopi darat (kopdar) tetaplah menjadi kebutuhan pengguna media sosial di Indonesia. Twitwar yang berujung duel dapat dikatakan merupakan bentuk lain dari keinginan berkumpul atau bertemu secara fisik, namun dalam konteks berkelahi. Karenanya sistem sosial budaya suatu masyarakat merupakan faktor penting yang juga turut berkontribusi dalam membentuk karakteristik pengguna media sosial.

Dalam konteks penggunaan media sosial Twitter sebagai saluran kampanye, faktor sistem sosial budaya komunal dan budaya lisan ini telah bertransformasi dan menemukan bentuk barunya 
melalui format kuliah Twitter (kultwit) dan perang kicauan (twitwar), dimana 140 karakter huruf yang disediakan Twitter kemudian di siasati untuk dapat menyampaikan pesan secara tertulis dengan panjang lebar yang kemudian dikenal dengan terminologi kultwit / kuliah melalui Twitter atau (Twitter Lecturing).

Terminologi kuliah melalui Twitter / kultwit dapat dikatakan sebagai pengejawantahan budaya lisan yang kemudian bertransformasi dalam bentuk budaya texting tertulis melalui twit / kicauan berseri di Twitter. Dalam format kultwit tersebut dapat terlihat bagaimana ragam konten yang tertuang dalam isi kicauan tidak ubahnya menjadi semacam budaya oral / lisan yang telah melekat dalam kultur masyarakat Indonesia pada umumnya. Sementara kultur komunal di Twitter dapat dijumpai dalam bentuk kegiatan "gotong royong" dan "keroyokan" untuk menjadikan suatu hastag (\#) baik berupa kata, frasa atau kalimat agar dapat menjadi trending topic.

Penggunaan format kultwit dan twitwar sebagai pola pendistribusian pesan politik di Twitter sekaligus menunjukkan bagaimana perbedaan karakteristik antara pengguna Twitter di Indonesia dengan pengguna Twitter di Amerika. Berdasarkan studi yang dilakukan oleh Boynton et al (2014) pola karakteristik pengguna Twitter di Amerika dalam mengunggah pesan politik biasanya hanya menggunakan satu kicauan tunggal berupa penggunaan tanda pagar (hastag \#), retweet ataupun mengirimkan link url website tertentu. Sementara format twitwar dan kultwit dalam mengunggah kicauan di Twitter ini secara umum seolah menjadi semacam karakteristik khas bagi pengguna Twitter di Indonesia.

Menurut catatan Parikesit dalam kolom telematika portal detik.com (31/07/2013) disebutkan bahwa sangat tidak umum dijumpai pengguna / user Twitter di Amerika dan Eropa yang menggunakan format kultwit untuk sharing pengetahuan kepada followernya. Perbedaan dalam menggunakan Twitter ini sekaligus menegaskan bagaimana kultur sosial budaya dalam suatu masyarakat memiliki pengaruh signifikan terhadap bagaimana cara mereka dalam mengunggah kicauannya di Twitter. Temuan ini sekaligus mengkonfirmasi hasil penelitian yang dilakukan Brock (2013) yang mengkaji bagaimana Twitter digunakan oleh komunitas Amerika berkulit hitam (black American) sebagai medium untuk mengkomunikasikan kebudayaan mereka layaknya seperti percakapan lisan.

Dalam perspektif komunikasi politik, format kultwit dan twitwar yang diunggah oleh kedua pendukung capres dapat pula dikategorikan ke dalam bentuk permainan katakata (the word play of political). Sebagaimana dikemukakan Nimmo (2000), pertarungan dan permainan kata-kata menjadi sesuatu yang sangat penting dalam komunikasi politik. Permainan kata-kata dalam politik (the word play of political) ini kemudian turut pula mengejala dan hadir melalui penggunaan saluran komunikasi kontemporer, hanya saja bentuknya yang kemudian bertranformasi melalui format kultwit dan twitwar.

Dengan demikian, kehadiran format kultwit dan twitwar harus pula dipandang sebagai permainan kata-kata untuk mengkonstruksi realitas politik dengan tujuan membentuk opini publik. Setiap ekspresi, sikap, gagasan, ide maupun pandangan pendukung capres yang termanifestasikan dalam format unggahan kicauan mereka, merupakan bentuk dari permainan pesan-pesan politik yang bertujuan untukmempengaruhiopinipublik. Bagaimanapun seperti dijelaskan McNair (2011) bahwa aspek pembentukan opini publik merupakan salah satu tujuan utama dalam komunikasi politik, karena hal itu akan mempengaruhi pencapaianpencapaian politik para aktor politik.

\section{Kesimpulan}

Kultwit dan twitwar biasanya digunakan oleh akun Twitter pendukung capres untuk mengunggah kicauan yang bertujuan untuk menginformasikan dan sekaligus menyerang masing-masing kandidat capres. Maraknya penggunaan format twitwar dan kultwit dalam kicauan akun Twitter kedua pendukung kandidat capres dapat dikatakan merupakan transformasi 
dari bentuk "bersilat lidah" dan budaya gosip secara lisan yang menemukan bentuk barunya melalui budaya tekstual. Sehingga 140 karakteristik huruf yang difasilitasi Twitter untuk dapat mengungah kicauan, kemudian disiasati dalam bentuk perang kicauan (twitwar) dan kuliah twitter (kultwit) / kicauan berseri.

Penggunaan kedua format tersebut seolah menegaskan kembali bagaimana kultur lisan dan budaya komunal pada masyarakat Indonesia ternyata mampu beradaptasi dalam lingkungan digital yang memusatkan interaksinya melalui pertukaran pesan secara tekstual. Pertukaran pesan tekstual yang menjadi basis interaksi di media sosial (Twitter) pada kenyataanya malahan menjadi medium baru bagi kedua pendukung capres untuk memperbincangkan sosok capres yang mereka dukung selama masa kampanye pilpres 2014. Layaknya percakapan lisan, format kultwit dan twitwar dipandang mampu meningkatkan kuantitas pesan politik yang bersirkulasi selama masa kampanye pilpres 2014. Hal inilah yang kemudian dapat menjelaskan mengapa selama masa kampanye pilpres 2014, Indonesia mencatatkan kicauan lebih dari 95 juta kicauan.

\section{Daftar Pustaka}

Abugaza, Anwar. 2013. "Social Media Politica, Gerak Massa Tanpa Lembaga”. Tangerang: Tali Writing \& Publishing House. Arianto, Bambang. 2015. "Kampanye Kreatif dalam Kontestasi Presidensial 2014". Jurnal Ilmu Sosial dan Ilmu Politik. Vol. 19 No.1 Budiman, Ahmad. 2014. "Kampanye Hitam Pemilu Presiden 2014". Info Singkat Pemerintahan Dalam Negeri. Vol 6. No.11. P3DI. Brock, Andre. 2012. "From the Blackhand Side: Twitter as Cultural Conversation". Journal of Broadcasting \& Electronic Mediavol.56,4.hlm.529-549. Routledge.

Brock, Andre.2016. "Critical Technocultural Discourse Analysis"

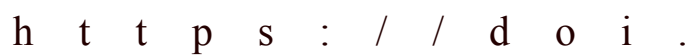
org/10.1177/1461444816677532 Boynton, G.R et al. 2014. "The Political Domain Goes to Twitter: Hastags, Retweets and URLs". Open Journal of Political Science. Vol.4, 1. hlm. 8-15. Connover, M.D. et al. 2011. "Political Polarization on Twitter". Association for the Advencement of Artificial Intelegent. (www.aaai.org)

Lim, Merlyna. 2012. "Life is Local in the Imagined Global Community: Islam and Politics in The Indonesian Blogosphere." Journal of Media and Religion. 11:3, 127-150. Routledge. McNair, Brian. 2011. "An Introduction To Political Communication” Edisi ke-5. New York: Routledge Francis and Taylor. Mulyana, Deddy. 2013. "Komunikasi Politik Politik Komunikasi. Membedah Visi dan Gaya Komunikasi Praktisi Politik”. Bandung: Remaja Rosda Karya.

Nimmo, Dan. 2000. "Komunikasi Politik: Khalayak dan Efek". Bandung: Remaja Rosda Karya. Nugroho, Yanuar. 2011. @ksi warga: Kolaborasi DemokrasiPartisipatoris,danKebebasan Informasi- Memetakan Aktivisme sipil kontemporer dan penggunaan media sosial di Indonesia. Laporan. Kolaborasi Penelitian antara Manchester Institute Of Inovation Research, university of Manchester dan Hivos Regional Southeast Asia. Manchester dan Jakarta: MIOIR dan Hivos. Vergeer, Maurice dan Liesbeth Hermans. 2013. "Campaingning on Twitter: Microblogging and Online Social Networkingas CampaignToolsinThe 2010 General Elections in The Netherlands". Jornal of Computer-Mediated Communication 18, hlm. 399-419.

\section{Internet}

"Twitter suarakan 95 Juta Kicauan Pilpres" https://m.detik.com/inet/cyberlife/d/2635682/ 
twitter-suarakan-95-juta-kicauan-pilpres diakses 29 Agustus 2015

"Warga Indonesia Raih Golden Tweet Sejagat 2014"

h t t p s : / / d u n i a.te mpo.co/read/ news/2014/12/13/118628237/warga-indonesiaraih-golden-tweet-sejagat-2014 29 Agustus 2015 "Akun Bot di Twitter Marak Menjelang Pilpres" http://ictwatch.com/internetsehat/2014/06/23/ akun-bot-di-twitter-marak-menjelang-pilpres diakses 29 Agustus 2015

"Menyoal Fenomena Kultwit di Indonesia" http://inet.detik.com/read/2013/7/31/100129/ 2319727/398/menyoal-fenomena-kultwit-diindonesia diakses, 10 Desember 2013
"Terkait Pemilu, Petinggi Twitter Temui Pasangan Capres"

http://news.detik.com/read/2014/06/03/1808 08/2598800/1562/ada-421-juta-tweet-terkaitpemilu-petinggi-twitter-temui-pasangan-capresdiakses, 3 Juni 2014

\section{"Para Caprespun di Pepeti Twitter"}

http://inet.detik.com/read/2014/06/04/143455/2 599599/398/para-capres-pun-idipepeti-twitterdiakses 04 Juni 2014. 